\title{
Nuclear Fuel Cycle and Supply Chain (NFCSC) Technical Monthly November FY-20
}

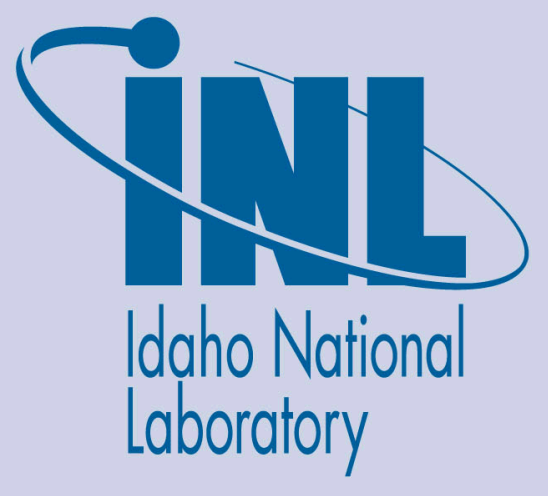

The INL is a U.S. Department of Energy National Laboratory operated by Battelle Energy Alliance 


\section{DISCLAIMER}

This information was prepared as an account of work sponsored by an agency of the U.S. Government. Neither the U.S. Government nor any agency thereof, nor any of their employees, makes any warranty, expressed or implied, or assumes any legal liability or responsibility for the accuracy, completeness, or usefulness, of any information, apparatus, product, or process disclosed, or represents that its use would not infringe privately owned rights. References herein to any specific commercial product, process, or service by trade name, trademark, manufacturer, or otherwise, does not necessarily constitute or imply its endorsement, recommendation, or favoring by the U.S. Government or any agency thereof. The views and opinions of authors expressed herein do not necessarily state or reflect those of the U.S. Government or any agency thereof. 


\section{Nuclear Fuel Cycle and Supply Chain (NFCSC) Technical Monthly November FY-20}

Idaho National Laboratory Idaho Falls, Idaho 83415

http://www.inl.gov

Prepared for the

U.S. Department of Energy

Office of Nuclear Energy

Under DOE Idaho Operations Office

Contract DE-AC07-05ID14517 



\section{CONTENTS}

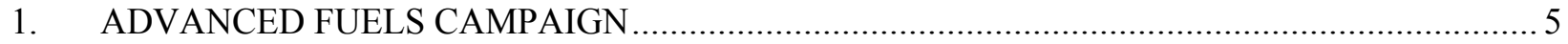

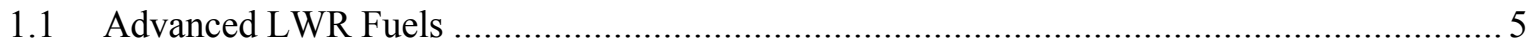

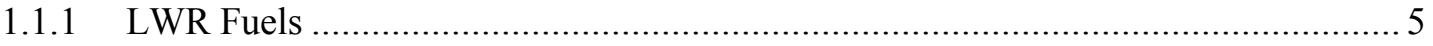

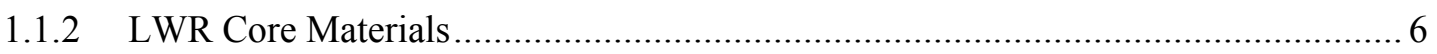

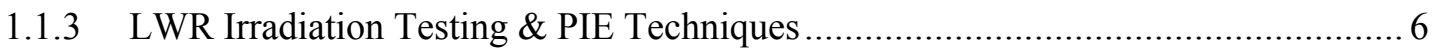

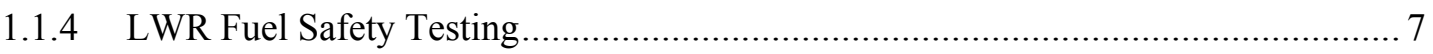

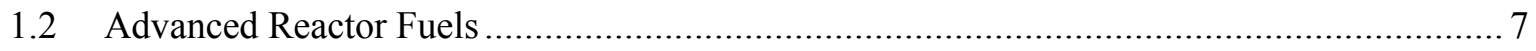

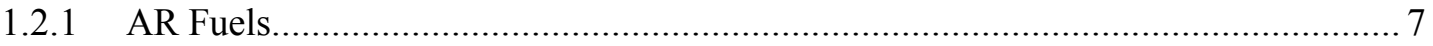

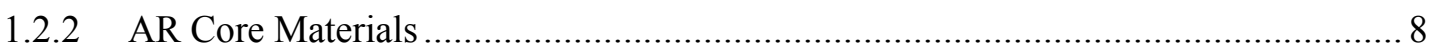

1.2.3 AR Irradiation Testing \& PIE Techniques .......................................................... 9

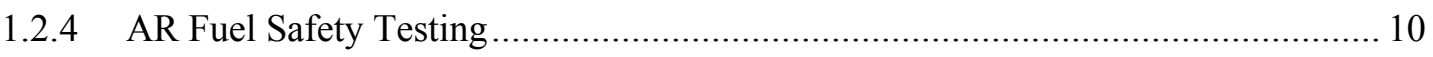

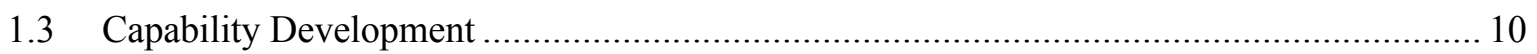

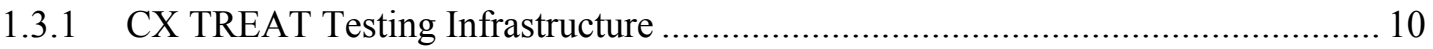

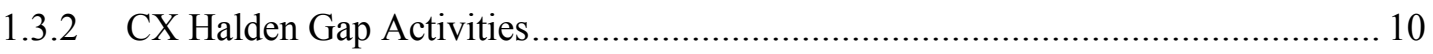

2. MATERIAL RECOVERY AND WASTE FORMS DEVELOPMENT ..................................... 12

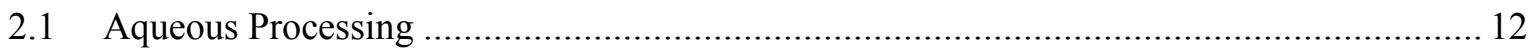

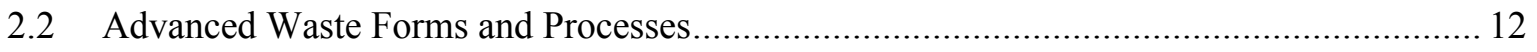

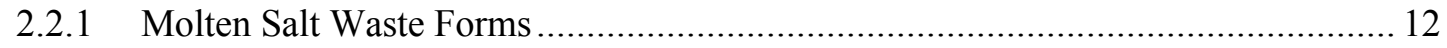

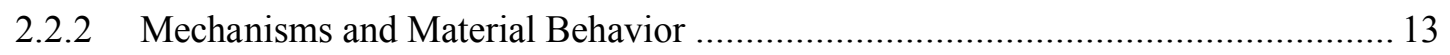

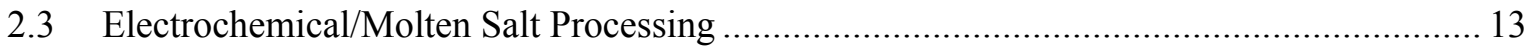

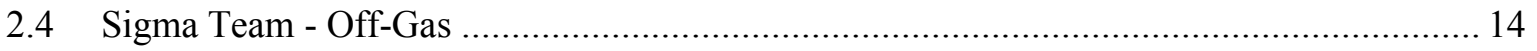

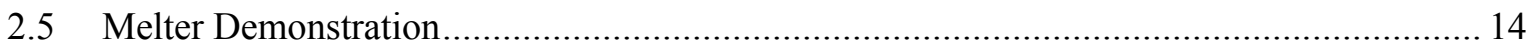

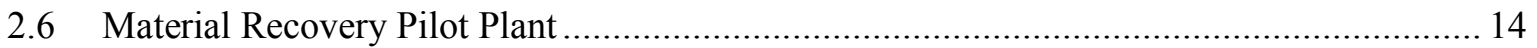

2.7 Polishing and Solidification (Extraction, Conversion, Downblending) ............................. 15

2.8 Early Design of Engineering Scale Demonstration ...................................................... 15

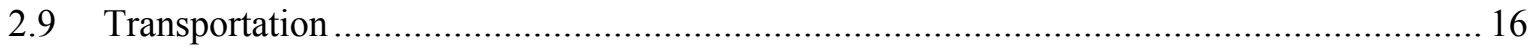

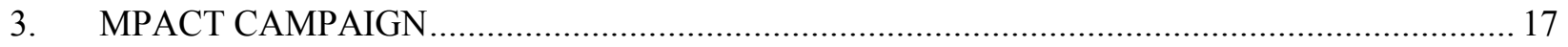

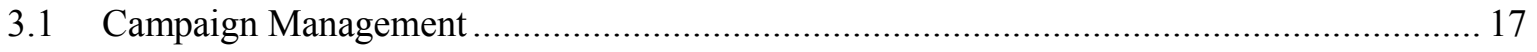

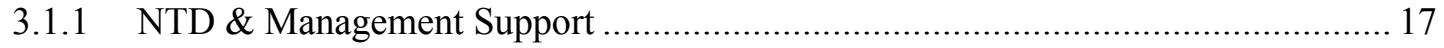

3.2 MRWFD/Advanced Nuclear Safeguards and Security Research................................... 17

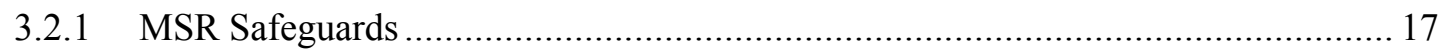

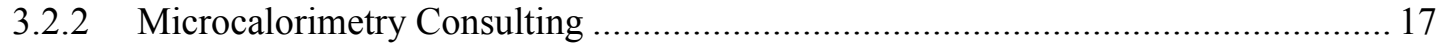

3.3 Safeguards and Security Supporting Technologies - Echem...................................... 17

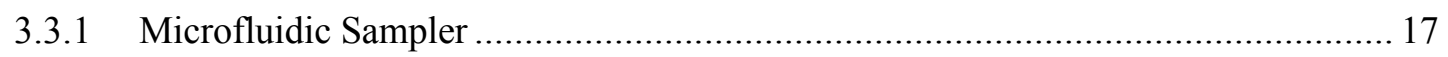

3.3.2 Bubbler for Measuring Density and Depth of Molten Salt ................................. 18

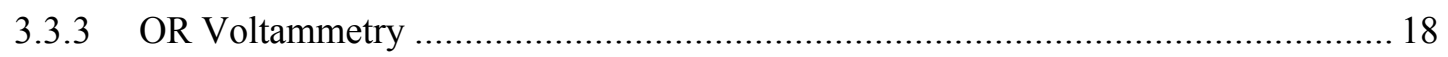




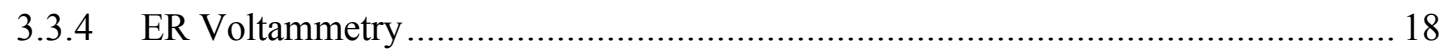

3.4 Safeguards and Security Milestone 2020 - Echem: ..................................................... 18

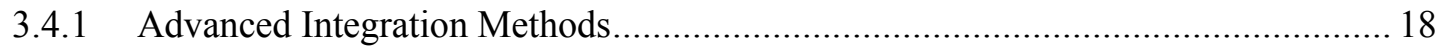

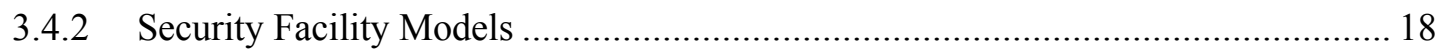

4. SYSTEMS ANALYSIS AND INTEGRATION (SA\&I) CAMPAIGN .................................... 19

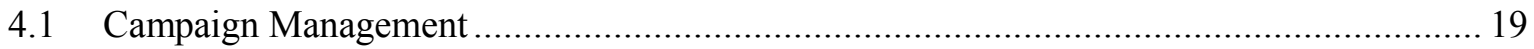

4.2 NUCLEAR ENERGY SYSTEM PERFORMANCE (NESP) ........................................ 19

4.2.1 Technology Maturity \& Economic Performance Potential of Micro-reactors ......... 19

4.2.2 Impacts of Foreign Energy Transition Policies .................................................. 19

4.2.3 Factors Impacting Nuclear Energy Share .......................................................... 19

4.2.4 Maintain/Update of Fuel Cycle Catalog............................................................ 19

4.2.5 Transition Analysis Studies and Tools Development ........................................... 19

4.2.6 Quick Turn-Around Studies ..................................................................... 20

4.3 ECONOMIC AND MARKET ANALYSIS FOR NUCLEAR ENERGY SYSTEMS

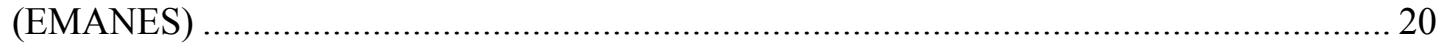

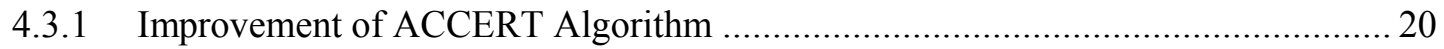

4.3.2 Daily Market Analysis of Load Following and Storage Impacts............................ 20

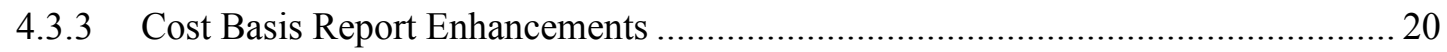

5. JOINT FUEL CYCLE STUDY ACTIVITIES .................................................................... 21

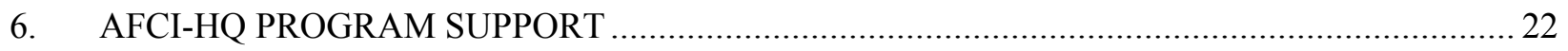

6.1 Innovations in Nuclear Technology R\&D Awards .................................................... 23

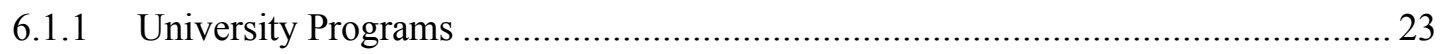

\section{FIGURES}

Figure 1. Images produced from x-ray computed tomography of irradiated UN TRISO particles

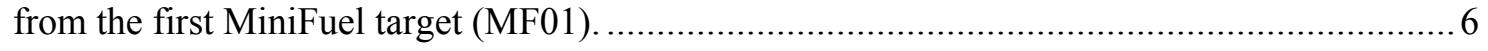

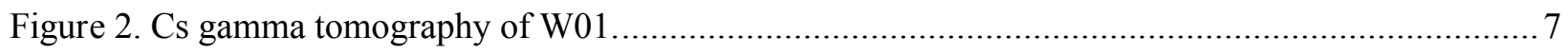

Figure 3. Mockup FAST rodlet (lower) and SI (upper) and OA (middle) inner capsules........................ 8

Figure 4. Uranium enrichment and forms for advanced reactor concepts. ......................................... 10

Figure 5. Results of PCT conducted with HM glass at different imposed pH values. .......................... 13 


\title{
Nuclear Fuel Cycle and Supply Chain (NFCSC) Technical Monthly November FY-20
}

\section{ADVANCED FUELS CAMPAIGN}

\author{
1.1 Advanced LWR Fuels
}

\subsubsection{LWR Fuels}

[INL] For a furnace upgrade to provide a new hydrogen atmosphere furnace capability, all necessary mechanical and detection system drawings were completed. A work request was submitted to install the necessary hydrogen system building upgrades. Parts for the detection system were ordered. (M. Cole)

[LANL] A paper titled, "Advanced Post irradiation Characterization of Nuclear Fuels Using Pulsed Neutrons," was published in the Journal of Materials (JOM) special issue on "Advanced Characterization and Testing of Irradiated Materials." JOM is the Member Journal of The Minerals, Metals \& Materials Society and paper hardcopies are distributed to all member. The paper is authored by Sven Vogel and describes efforts at LANSCE to characterize irradiated nuclear fuels using pulsed neutrons. Pulsed neutrons offer characterization not available with $\mathrm{CW}$ neutrons such as the reactor source at INL. The paper results from a collaboration by researchers from LANL (S.C. Vogel, M.A.M. Bourke, A.M. Long, K.J. McClellan, C.T. Kelsey), INL (A.E.Craft), ORNL (J. Harp), TU Munich (A.S. Losko), TU Darmstadt (M. Roth), and UC Berkeley (J. Lin, P. Hosemann, A.S. Tremsin). (https://doi.org/10.1007/s11837-019-03849-2). (S. Vogel)

[LANL] A publication titled, "Temperature-Dependent Crystal Structure of U3Si2 by High Temperature Neutron Diffraction," was accepted in Materialia. The manuscript details investigations into the high temperature anisotropic thermal expansion in stoichiometric U3Si2 and U3Si2.01 using neutron diffraction. Significant differences in the thermal expansion behavior were identified between the two compositions and compared with recent DFT simulations to elucidate the impact that crystalline defects have on the properties of U3Si2. This work is a collaborative effort summarizing work that was conducted between the AFC and NEAMS providing data for how U3Si2 will perform under burnup. (T.L. Wilson, S. Vogel, J. White)

[LANL] High temperature nanoindentation of UB2 and UB4, candidate phases for advanced fuels, was performed in a Hysitron Triboindenter in an argon environment to measure the change in hardness and elastic modulus. UB4 was successfully indented to $500{ }^{\circ} \mathrm{C}$ while UB2 was successfully indented to 400 ${ }^{\circ} \mathrm{C}$. At temperatures greater than these, the surface of the samples started to oxidize, inhibiting accurate measurements. The complete data analysis is ongoing but initial results show a linear decrease in the elastic modulus with temperature. (D. Frazer, E. Kardoulaki)

[ORNL] Doping UO2 using Cr2O3 was investigated using a few different temperatures to determine if a pre-heat treatment of the samples helps increasing their average grain sizes. Since literature reports that Cr solubilization occurs at $1100-1200{ }^{\circ} \mathrm{C}$ and $\mathrm{Cr} 2 \mathrm{O} 3$ tends to dissociate at $\sim 1470{ }^{\circ} \mathrm{C}$, two experiments were carried out at 1150 and $1465^{\circ} \mathrm{C}$ temperatures. Another sample was sintered at $1655^{\circ} \mathrm{C}$ following the above heat treatments. The first sample heated at $1150^{\circ} \mathrm{C}$ showed only partial grain growth, while an average grain size of $5 \pm 3 \mu \mathrm{m}$ was obtained for the sample heat treated up to $1465^{\circ} \mathrm{C}$. The third sample processed at 1150,1465 , and $1655^{\circ} \mathrm{C}$ temperatures only produced a sample consisting an average grain size of $12 \pm 6 \mu \mathrm{m}$. Also, all three samples showed good terminal densities with a range of $95-97 \% \mathrm{TD}$. Three more samples were fabricated by varying pellet (green) making pressure $(66,117$, and $272 \mathrm{MPa}$ ) 
and holding for $1 \mathrm{~h}$ at 1150 and $4 \mathrm{~h}$ at $1650{ }^{\circ} \mathrm{C}$ before ramping up to $1750{ }^{\circ} \mathrm{C}$ at which the samples were held for another $10 \mathrm{~h}$. While the densities of these sintered pellet samples were in a $95-96 \% \mathrm{TD}$ range, pellets made using 66,117 , and $272 \mathrm{MPa}$ had average grain sizes of $16 \pm 7 \mu \mathrm{m}, 17 \pm 8 \mu \mathrm{m}$, and $18 \pm 9$ $\mu \mathrm{m}$, respectively. These experiments indicated that pre-heat treatments of the samples to increase $\mathrm{Cr}$ dissolution in UO2 matrix had no significant and/or favorable effects. (A. Nelson)

[ORNL] Postirradiation examination of the first irradiated MiniFuel target (MF-01) continued. This irradiation contained several uranium nitride kernel variants that could be deployed in advanced coated particle fuel concepts. Several particles were examined by x-ray computed tomography including one of the UN TRISO coated particles. These results show that XCT can still be applied to the kernels irradiated in MiniFuel which are larger and were discharged from the reactor more recently than particles previously examined by this technique. It was possible to measure kernel volume for the uncoated particles and kernel volume and layer thickness for the coated UN TRISO particles. More XCT is planned on the other available irradiated UN TRISO particles. Further optical microscopy was performed and scanning electron microscopy examinations of MiniFuel particles were initiated. (J. Harp)
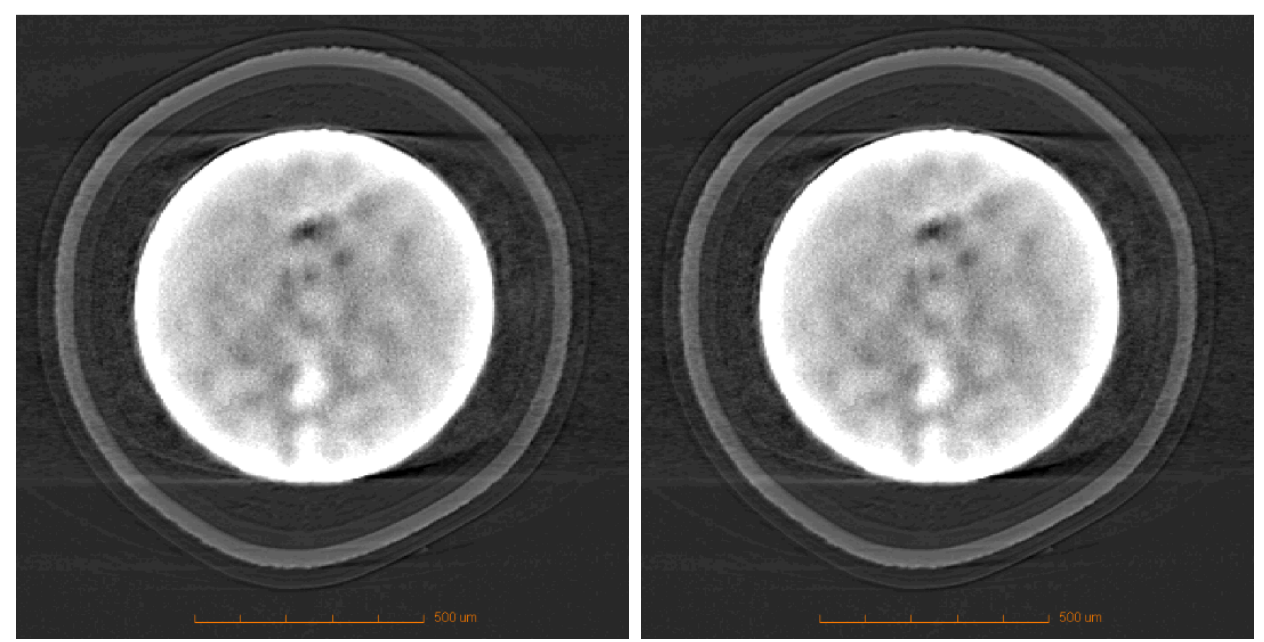

Figure 1. Images produced from x-ray computed tomography of irradiated UN TRISO particles from the first MiniFuel target (MF01).

\subsubsection{LWR Core Materials}

[INL] First batch Sample preparation was completed. First batch pressure resistance weld (PRW) of MA957 was attempted but the PRW system is having issues. These issues are currently being resolved. (J. Gan)

\subsubsection{LWR Irradiation Testing \& PIE Techniques}

[INL] After $\sim 184$ effective full power days of irradiation, ATF-2 was reconfigured to ATF-2B1, assembled, installed into the Advanced Test Reactor 2A Loop, and began irradiation. The ATF-2B1 configuration includes boiling-water-reactor type rodlets in Tiers 3 and 4 and pressurized-water-reactor type rodlets in Tiers 1, 2, and 5 at more prototypical pressure and temperature. During reconfiguration, hardware problems associated with the test train and experiment handling tools slightly delayed experiment insertion, however, the project team was able to resolve those issues and still meet the cycle 166B insertion target in early November. (G. Hoggard)

[INL] Preliminary design and analysis efforts to support new ATF-1 scope for Framatome are making progress. Fabrication of capsule components and gauges has completed. Preliminary enrichments for the 
design specifications of the fuel rodlet have now been validated by Framatome. Conceptual design of ATF-CC (cladding creep) experiment is on-going. The 166B-1 cycle is on-going, with anticipated shutdown of 1/10/2020. Preparations for the 168A-1 cycle will commence next month. (C. Murdock)

[INL] Gamma tomography on five ATF-1 rodlets has commenced. One rodlet (ATF-W01) contained U3Si2 fuel and Zirlo cladding, two rodlets (ATF-WB2 and ATF-WB6) had UN-U3Si2 fuel and Zirlo cladding. The last two (ATF-L41 and ATF-L44) had UN-U3Si5 fuel and FeCrAl Kanthal-AF cladding. The first three rodlets were sponsored by Westinghouse, whereas the last two rodlets were sponsored by LANL. Cs gamma tomography of W01 is shown in the Figure 2 below. Design of fixtures for ATF-2 pins has been completed. The fixtures are necessary to perform PIE on the rodlets in the hot cell. The first rodlets from phase 2 of the ATF campaign are expected to be received in HFEF in the coming months. (F. Cappia)

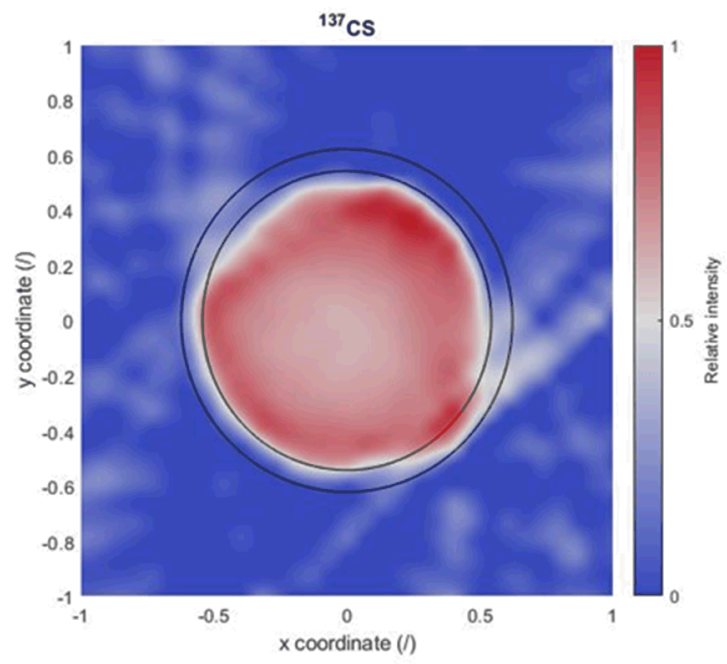

Figure 2. Cs gamma tomography of W01.

\subsubsection{LWR Fuel Safety Testing}

\subsubsection{LWR Modeling \& Analysis}

[ORNL] Fuel performance modeling activities during November have focused on the thermo-mechanical analysis of $\mathrm{SiC}-\mathrm{SiC}$ cladding with $\mathrm{SiC}$ and Zircaloy spacer grids, in order to understand the effect of the mechanical constraints imposed by spacer grids on the deformation and stress development in the SiC$\mathrm{SiC}$ cladding. The initial results indicate a significant increase in the cladding stress level resulting from these mechanical constraints, at levels above the proportional limit stress that will induce micro-cracking, although the constraint from the spacer grids does significantly reduce the lateral deformation and bowing that results from azimuthal neutron flux and power variations. This work is also investigating the impact of utilizing $\mathrm{SiC}$ spacer grids, rather than zircaloy grids, for which the preliminary results indicate the development of higher stress levels in the SiC spacer grids. (B. Wirth)

\subsection{Advanced Reactor Fuels}

\subsubsection{AR Fuels}

[INL] November has focused on FAST mock-up fabrication and welding development. Both rodlets and inner capsules were fabricated using prototypic hardware. Previous rodlet welding was developed using 316L hardware versus HT-9. During development weld parameters were modified to increase heat input 
due to the alloy change and endplug dimensions were changed slightly to aid in assembly. Both outboard A (OA) and small I (SI) inner capsules were loaded with filler material to simulate the appropriate amount of inner volume. Figure 3 shows both inner capsules and rodlets.

In addition to FAST development several diffusion couples were made with $\mathrm{Zr}$ and U-10Zr. $\mathrm{Zr}$ has been proposed as a fuel cladding chemical interaction barrier, however, it is also known that zirconium has will readily diffuse through uranium as well. These diffusion couples will aid in determining the minimal amount of zirconium barrier that is needed to ensure an adequate barrier remains through the irradiation cycle. (R. Fielding)

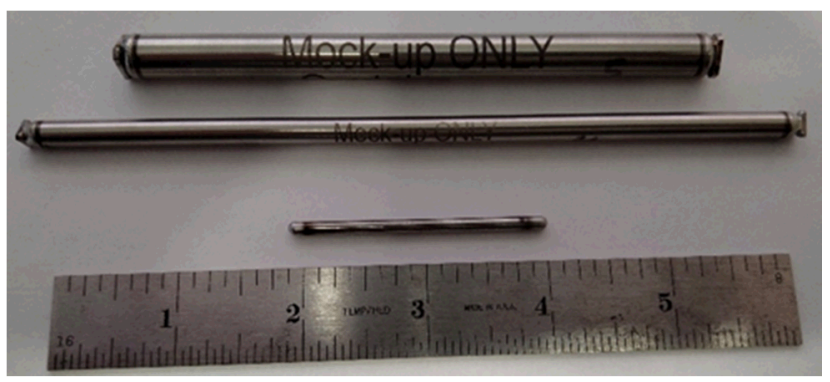

Figure 3. Mockup FAST rodlet (lower) and SI (upper) and OA (middle) inner capsules.

[INL] Additions for the next Metallic Fuels Handbook have been identified and planned for FY 20. (J. Giglio)

[ORNL] The specific design calculations for the Uranium Zirconium alloy MiniFuel irradiation targets were initiated. Neutronic calculations are on-going to determine the optimum volume of fuel that can be loaded into a MiniFuel capsule. (J. Harp)

\subsubsection{AR Core Materials}

[LANL] Results of high dose shear punch and hardness testing of HT-9 and 14YWT after irradiation in the BOR-60 reactor to doses up to 30 dpa were presented at the quarterly update meeting for the HighFidelity Ion Beam Project at Penn State University. (B. Eftink)

[PNNL] Initial examinations of the three 9Cr alloys fabricated for milestone M4FT-19PN020302022, "Conduct 9Cr Alloys Development and Testing at PNNL and Write Report," continued this month. All hardness testing was completed, and SEM examinations are in progress. (M. Toloczko)

[PNNL] Pilger fabricated 14YWT tubing material for milestone M4FT-20PN020302022 was obtained. (M. Toloczko)

[PNNL] Planning for ion irradiations in support of milestone M3FT-20PN020302021 was started. Texas A\&M, where the ion irradiations will be performed, has been contacted and space in their schedule has been reserved. (M. Toloczko)

[LANL] Samples were machined and polished from 14YWT tubing produced by pilger processing and hydrostatic extrusion to perform high dose ion irradiations at 450C to investigate swelling resistance in these alloys. (S. Maloy)

[ORNL] The 4th High Precision Tube Rolling (HPTR) cold rolling of the four tubes of OFRAC was completed by Nippon Fuel Development (NFD), Japan. Small end cracks formed on the OR9, OR11 and OR12 tubes and were removed and sent to ORNL for vacuum annealing and hardness evaluations. The challenge and highlight of this tube fabrication effort is that the final dimension of the thin wall tubing 
will be $6 \mathrm{~mm}$ outer diameter, $0.5 \mathrm{~mm}$ wall thickness and lengths estimated to be more than $1 \mathrm{~m}$. (D. Hoelzer/Massey)

[ORNL] The end sections of $1 \mathrm{~cm}$ length were cut from the $6 \mathrm{SS}-3$ type tensile specimens with extended grip lengths of 14YWT (PM1 heat) that were tested in the forced convection sodium (Na) loop at Argonne National Laboratory. This procedure resulted in the standard dimension of SS-3 tensile specimens that will fit the grips for tensile testing. The $1 \mathrm{~cm}$ length ends will be prepared by metallographic procedures both edge on and planar for microstructure characterization studies. Two control SS-3 tensile specimens of 14YWT-PM1 were also prepared with this procedure. This research will help in understanding the corrosion behavior of 14YWT exposed to molten $\mathrm{Na}$ in test environment and conditions that are representative of Sodium Fast Reactors. (D. Hoelzer)

[ORNL] The manuscript titled, "Modern nanostructured ferritic alloys: a compelling and viable choice for sodium fast reactor fuel cladding applications," was published in the Journal of Nuclear Materials, 2020, NUMA 151928. The author and co-authors of this manuscript are David Hoelzer (ORNL), Caleb Massey (ORNL), Steve Zinkle (UTK), Doug Crawford (INL) and Kurt Terrani (ORNL). (D. Hoelzer)

[PNNL] As part of the program to advance the technology associated with fabricating tubing from difficult-to-fabricate materials, the PNNL rolling mill has been modified so that it can perform pilgering of thick-wall tubes. This capability to pilger thick-wall tubes into finished thin-wall tubing establishes a unique R\&D capability within the DOE complex.

As part of the plan for this fiscal year to pilger extended length 14YWT thin-wall tubes, thick-wall tubes are being prepared. These form the initial feed stock for the pilgering run. An initial run will be made with MA956 to check out the operation of the pilger mill with the extended length actuator. Upon completion of the MA956 run, 14YWT will be pilgered.

A short sample has been cut from the 14YWT tube pilgered last fiscal year. This sample will be sent to the team performing ion irradiations. This team will assess the performance of 14YWT under ion irradiation to high dpa. (R. Omberg)

\subsubsection{AR Irradiation Testing \& PIE Techniques}

[INL] The FAST-1 group of experiments has concluded the final design phase. The final drawings, enrichments, temperature and structural analyses have been reviewed and issued. The final design review has completed and will officially close out in early December. Fabrication is complete for the outer capsule components. The inner capsule components are making good progress and will finish in early January. Rodlet component fabrication will finish in January as well. Programmatic analysis completed after the reactor startup due to the short outage. The 166B-1 irradiation cycle is on-going and is anticipated to complete 1/10/2020. Preparations for the 168A-1 irradiation cycle will commence in December. (C. Murdock)

[INL] Baseline PIE on legacy EBR-II fuel continue with tomography in progress on 2 fuel pins (X496CL47 and X486-J555). Development of a PIE plan for the FAST irradiation experiment has started. The PIE plan will fulfill an L4 milestone in mid-December. Preparation of several metallic fuel samples for electron microscopy is ongoing in HFEF. Electron microscopy will shed light on microstructure features and fuel performance at micro scale. (L. Capriotti)

[INL] For the in-cell whole pin testing furnace a draft of the software interface design was completed, and a design review was held. Comments are being incorporated and programming adjusted. Modules that were ordered to support the furnace system have been delivered. Development of the Phase I and II Qual Plans began. (M. Cole) 


\subsubsection{AR Fuel Safety Testing}

[ANL] Fuel forms of advanced reactor concepts have been reviewed and required uranium enrichment is summarized in Figure 4. More than fifty advanced reactor concepts with wide range of power rates and fuels forms are currently under development in the United States, and some of them veiled their fuel forms. In general, many advanced reactor concepts are looking for higher enriched uranium (10-20\%) with various forms, which include oxide, metal alloy, nitride, carbide, TRISO, silicide, hydride, molten form, etc. (T. Kim)

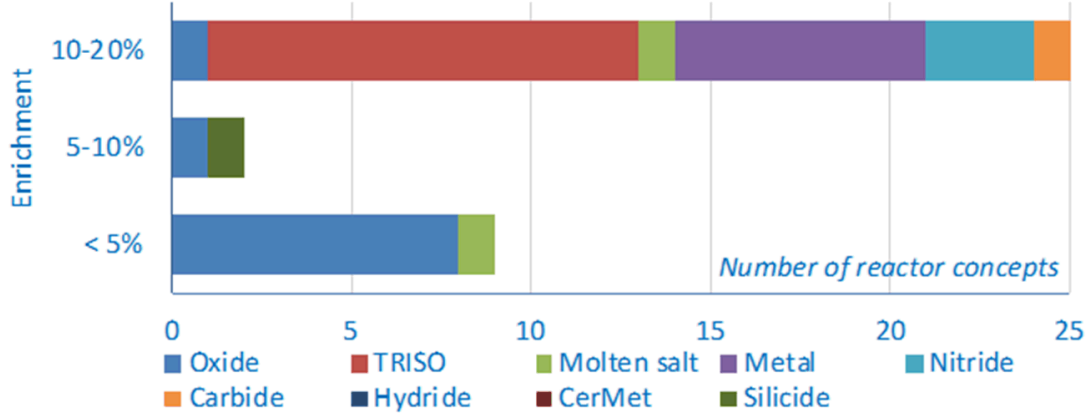

Figure 4. Uranium enrichment and forms for advanced reactor concepts.

\subsection{Capability Development}

\subsubsection{TREAT Testing Infrastructure}

- [INL] New fittings for the IR detector and sample holder have been designed and fabricated. These items will enhance testing efficiency. (R. Schley)

\subsubsection{Halden Gap Activities}

\subsubsection{TREAT}

[INL] Irradiation on uranium silicide fuel in the SETH capsule was completed, thereby successfully completing the INL Level 2 milestone ahead of schedule. Preparations for work on a mixed enrichment MARCH-SERTTA capsule is still underway. The experiment data package and engineering calculation documents were updated to reflect the stack of mixed-enrichment pellets. Work on welding the rodlet has begun. (L. Emerson)

[INL] write up of the Super SERTTA vehicle option for LOCA testing was completed. Comparison analysis continued of MARCH-SERTTA based LOCA testing vehicle (LOCA-SERTTA) vs the Super SERTTA vehicle. (D. Dempsey)

[INL] Design modifications for handling pre-irradiated fuel in MARCH-SERTTA are well underway. The design team has been iterating on the design to ensure experiment objectives can be met with the proposed design changes. This process will continue until the modified design has been optimized. Preliminary radiological calculations have been performed to indicate the type of material and amount of shielding needed to handle the experiment. (L. Emerson)

[INL] Experiment support at TREAT continued. Work is ongoing on the underwater evaluation of pyrometers at the High Temperature Test Laboratory (HTTL). (T. Pavey)

[INL] Disassembly, visual inspections, sectioning and mounting of samples for microscopy of the SETH$\mathrm{D}$ and SETH-E tests was completed. Analysis of data is ongoing. Prepared and supported shipment 
planning of the MARCH-SERTTA-CAL test from TREAT to Irradiated Materials Characterization Laboratory (IMCL) for PIE. (M. Bybee)

[INL] Work continued on improvements to hydriding. (T. Pavey)

[INL] A mechanical testing fixture for hoop tension samples was designed, and a 3D printed version has been evaluated by HFEF engineers. With minor changes, the fixture will be ready for the hoop tension sample testing. A four-axis mill has been utilized for initial hoop tension sample machining. Three samples have been machined to assess the four-axis mill. A fuel cladding from HB Robinson plant is being identified for the fuel removal activity. $5-\mathrm{mm}$ full ring samples will be cut and sent to AL for the development of the fuel removal. (M. Bybee)

[INL] Support was provided for experiments in TREAT. An automated software tool is being developed to generate a preliminary data report for each experiment. The goal of the automated software is to be able to e-mail this report to each experiment's POC by the close of business of the same day as their transient. (T. Pavey)

[INL] The mechanical conceptual design was completed which allows us to verify the conceptual neutronics and thermal analysis in December and move on to preliminary design. (D. Dempsey)

[INL] Conceptual design for the sodium loop commissioning test is more than half complete. (T. Smuin)

[INL] The Heater Assembly for the CINDI experiment is complete and will be shipped to TREAT. The loading plan for CINDI is complete. (T. Smuin)

[INL] Research continued to resurrect old procedures on sodium handling to start discussions with HFEF personnel on past sodium work and the path forward for THOR PIE. (M. Bybee)

[INL] Equipment design/fabrication and procurement process continued for items related to in-cell fuel re-fabrication and capsule loading. (Table, Pit liner, 15-Cask equipment). (M. Bybee)

[INL] FOR-496 was completed, which included requirements for end cap and welding under pressure. The prototype end cap welding was completed on fuel rods. Development began of the modeling and system design for the end cap and welding under pressure systems. (M. Cole)

[INL] The funding determination meeting for the closure plate work was held and it was agreed that it will be done under operating funds. The cost estimate needs to be finalized before the funding determination is made final. (T. Maddock)

For more information on Fuels contact Steven Hayes (208) 526-7255. 


\section{MATERIAL RECOVERY AND WASTE FORMS DEVELOPMENT}

\subsection{Aqueous Processing}

[ONRL] Synthesis of (R,S)-mTDDGA has been initiated. The reaction between ethyl L-(-)-lactate and ethyl 2-bromopropionate in the presence of $\mathrm{NaH}$ is very rapid, with the reaction being completed within minutes (after the complete addition of ethyl 2-bromopropionate to the alkoxide) at $0{ }^{\circ} \mathrm{C}$. Based on the analysis using ${ }^{1} \mathrm{H}$ NMR spectroscopy, the ratio of diastereomers is 1:1.2, with the major stereoisomer being the undesired $(S, S)$-diastereomer. Longer reaction times or elevated temperatures do not lead to the substantial change in diastereomeric ratio (note that $\mathrm{NaH}$ was not used in excess). The mixture of diastereomers was then subjected to base promoted epimerization in the presence of lithium ethoxide in $\mathrm{EtOH}$. The epimerization of the stereocenter in $(S, S)$-isomer takes place, which leads to formation of the desired $(R, S)$-isomer. A diastereomeric ratio of 2:1 was observed after only $5 \mathrm{~h}$. The reaction will be continuously monitored to maximize the formation of $(R, S)$-isomer. The $(R, S)$-isomer in this reaction is the thermodynamic product, therefore, we are expecting nearly complete conversion of $(S, S)$-isomer into $(R, S)$-isomer. This will simplify the isolation of the desired product as well as maximize the yield. After the optimization of conditions, the reaction will be increased in scale.

The Ir-catalyzed C-H borylation does work (based

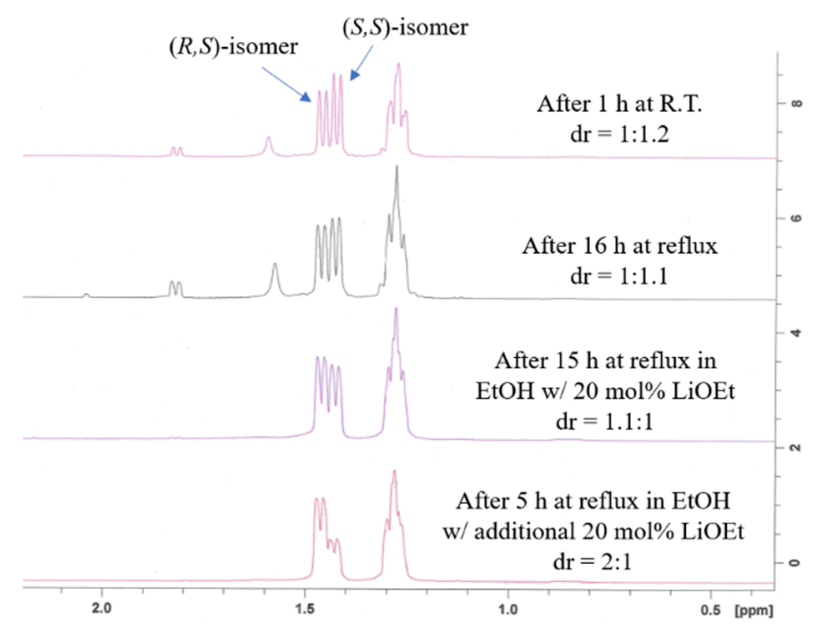
on the consumption of the starting material), however, it produces a complex mixture of products that cannot be separated. To simplify the synthesis of the desired functionalized product (and to test the selectivity of borylation - at $p$-position in pyridine or at the benzylic position), we are testing the Ircatalyzed C-H borylation on one of the precursors, methyl 6-(((2-(tert-butoxy)-2-

oxoethyl)amino)methyl)picolinate. This will allow us to selectively pre-functionalize the starting precursor before it is coupled with 2,6-bis(dibromomethyl)pyridine. Additionally, it will simplify the isolation/purification of the product. The new synthetic route will allow to form a tris-pyridine product with substitution at two instead of three sites.

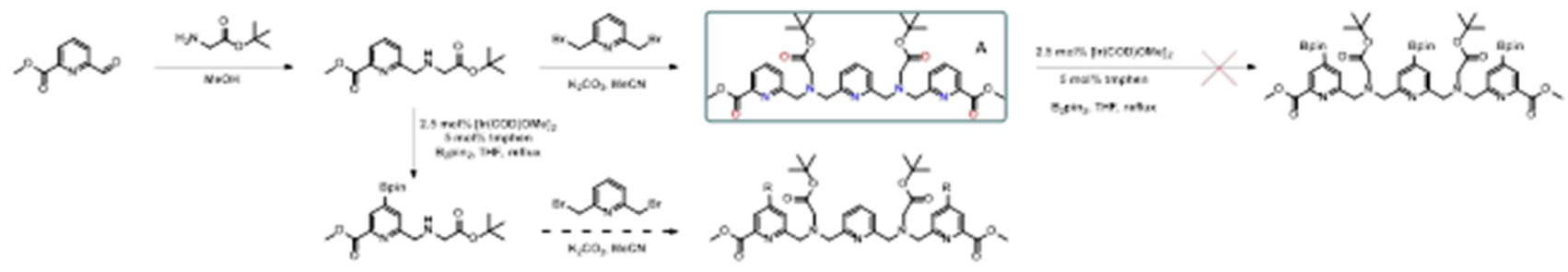

The starting material for the synthesis of DOTA-based ligand has not yet been delivered to ORNL (backordered), the expected delivery date is December 10. (S. Jansone-Popova)

\subsection{Advanced Waste Forms and Processes}

\subsubsection{Molten Salt Waste Forms}

[ANL] Immersion tests of extended durations remain in progress with iron phosphate waste form materials made during FY19. The tests are being continued to determine if the dissolution rate is 
eventually attenuated by either solution feedback effects or layer formation. The tests will likely be terminated in late December to perform surface analyses on the corroded specimens to determine if the glass or crystalline phases are corroding preferentially. (W. Ebert)

\subsubsection{Mechanisms and Material Behavior}

[ANL] Long-term tests with reference borosilicate glasses that were initiated in FY19 to measure the effect of $\mathrm{pH}$ on the onset of Stage 3 behavior in glasses representing waste glasses made at the DWPF remain in progress. Solution samples taken through about 208 days have been analyzed. Tests with HM glass showed the expected behavior in which tests conducted with higher imposed $\mathrm{pH}$ values triggered after shorter test durations. The normalized mass losses based on boron are shown in Figure 5. Test HM-1 was conducted without adjusting the $\mathrm{pH}$ and the initial $\mathrm{pH}$ values in tests with increasing index numbers were adjusted to $10.5,11.0,11.5,12.0,12.5$, and 13.0. The hypothesis being evaluated is that a threshold combination of $\mathrm{pH}, \mathrm{Al}, \mathrm{Si}$, and alkali metal solution concentrations is required to nucleate secondary phases that support Stage 3 corrosion behavior. The solution compositions measured in the series of tests with these glasses are being evaluated to determine a threshold combination that can be used to model all borosilicate waste glasses. (W. Ebert)

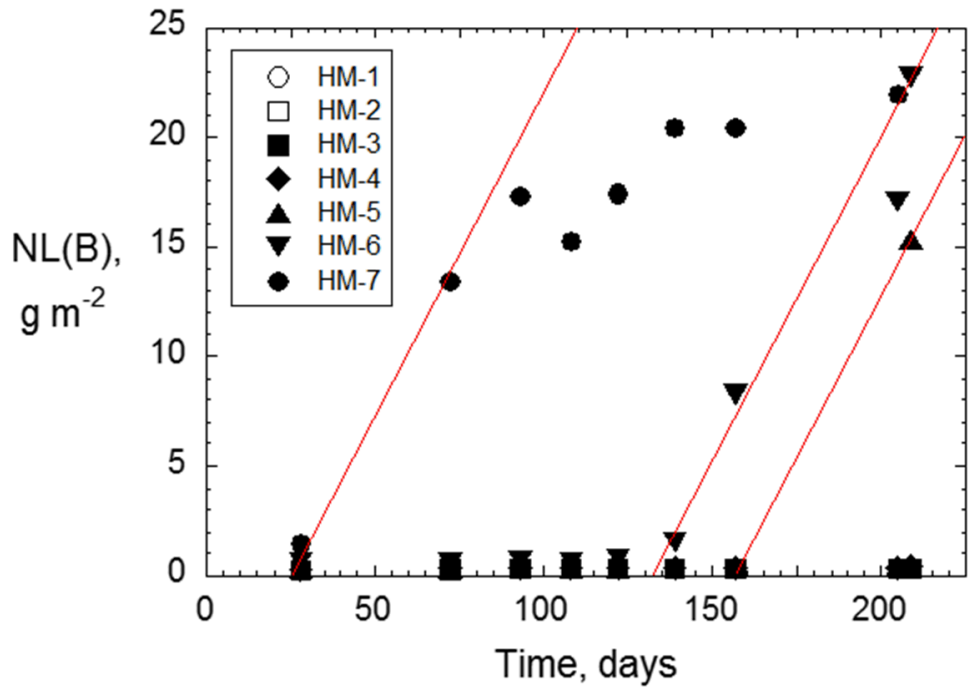

Figure 5. Results of PCT conducted with HM glass at different imposed pH values.

\subsection{Electrochemical/Molten Salt Processing}

[ANL] A test plan for experimental studies of molten salt chemistry was issued as ANL/CFCT-19/27. Work will improve our understanding of the redox chemistries of zirconium and uranium chlorides present in molten salts and complexes that form as a function of $\mathrm{pO}_{2}$ and $\mathrm{pCl}_{2}$. This will build on insights gained from a "deep-dive" study into zirconium chemistry in molten chlorides completed during FY18 and electrochemical measures of Zircaloy corrosion made during FY19. (W. Ebert)

[ANL] Design modifications to the anode baskets to accommodate kilogram-scale charges for the demonstration runs have been completed. Minor issues associated with the modular design were resolved. Presentations for the upcoming meeting in Japan were prepared and reviewed internally. Mark Williamson and Krista Hawthorne will present summary reviews of processing and waste form-related work being done at Argonne. (W. Ebert) 


\subsection{Sigma Team - Off-Gas}

[INL] The activity titled, "Support assessment of the off-gas system requirements/conceptual design for pyroprocessing of metallic UNF," was started on schedule in October 2019. The first phase of this activity is to support ORNL on an ORNL Level 4 milestone due January 31, 2020, to "Identify pyroprocessing off-gas characteristics, isotopes of concern and gaseous concentrations." A kickoff teleconference with ORNL and INL representatives of the Off-gas Sigma Team and the INL pyroprocessing team was held on November 6, 2019. Data collection began and several documents were provided for review. A second teleconference attended by ORNL and INL Off-gas Sigma Team representatives was held on November 27, 2019 to continue data collection and review. (N. Soelberg)

[ORNL] Two thin bed tests were completed that characterized the adsorption of $\mathrm{CH}_{3} \mathrm{I}$ by $\mathrm{AgZ}$ at $150^{\circ} \mathrm{C}$ with a $4.3 \mathrm{~m} / \mathrm{min}$ gas velocity. The first test (FY20-004) introduced $833 \mathrm{ppm} \mathrm{NO}$ and $833 \mathrm{ppm} \mathrm{NO} \mathrm{NO}_{2}$ to the dry air stream and the second test (FY20-005) added $2 \mathrm{wt} \%$ water to the $\mathrm{NO}_{\mathrm{x}}$ conditions. The $\mathrm{CH}_{3} \mathrm{I}$ concentration was $33 \mathrm{ppm}$. The sorbent used in FY20-004 was observed to gain $52 \mathrm{mg} / \mathrm{g} \mathrm{AgZ}$. The sorbent used in FY20-005 was observed to gain $73 \mathrm{mg} / \mathrm{g} \mathrm{AgZ}$. These are lower mass gains than observed in tests that did not include $\mathrm{NO}_{\mathrm{x}}$ or water $(97 \mathrm{mg} / \mathrm{g} \mathrm{AgZ}$ gain). These tests complete the experimental portion of this milestone. The iodine loading will be confirmed by neutron activation analysis. (R. Jubin)

[ORNL] An evaluation of Ru trapping methods was completed. A report has been drafted describing the challenges to recovery of Ru form dissolver off-gas (DOG) and recommending tests of three trapping materials. The first is a high surface area polymer to trap $\mathrm{RuO}_{4}$ immediately downstream of the dissolver system condensers, where the temperature is below $25^{\circ} \mathrm{C}$, is recommended for testing. High surface stainless steel wool and quartz (or ceramic) wool are two other deposition surfaces that can operate at elevated temperatures (e.g., $150^{\circ} \mathrm{C}$ to $300^{\circ} \mathrm{C}$ ) and should be tested. Deposition of $\mathrm{RuO}_{4}$ is enhanced at elevated temperatures, and such temperatures are needed to decompose nitrosyl ruthenium nitrates that may be entrained in the gas phase. In all cases, the deposited form is expected to be $\mathrm{RuO}_{2}$. The draft report is being reviewed by a team members and formal review is expected to commence the first week of December. (R. Jubin)

[ORNL] Teleconferences between INL and ORNL were held on 11/6/2019 and 11/27/2019. These teleconferences were focused on identifying potential resources and available literature relevant to the topic of pyroprocessing off-gas. The literature review supporting this milestone is underway. (R. Jubin)

\subsection{Melter Demonstration}

[INL] Design/build contracts were awarded for the canister, feed system, and off-gas systems. The fabrication drawings for the canister were approved. Services were procured from a local engineering company to perform the assembly design for the vitrification system as a whole. (E. Nef)

[PNNL] A draft melter test plan has been developed. Fabrication of melter components is approximately $25 \%$ complete. Design of the feed system is underway (B. Riley)

\subsection{Material Recovery Pilot Plant}

[ORNL] Two tests (runs 13 and 14) focused on using 60 mesh silica as the fluidizing media and extending the hydrochlorination run to a higher degree of completion were completed. In place of measuring and controlling the temperature of the coupon samples, the temperature of the bed in proximity of the sample was measured and controlled. In these tests, the coupons were "floating" unattached inside the fluidized bed, and they displayed a relatively uniform reaction along the entire surface of the coupons. This behavior is in sharp contrast to the behavior for the "fixed" coupons, where most of the reaction occurred at the bottom of the coupon. (R. Jubin) 


\subsection{Polishing and Solidification (Extraction, Conversion, Downblending)}

[INL] The lab scale demonstration successfully dissolved the EBR-II runt on November $11^{\text {th }}$. Samples of the strip, scrub, and raffinate were collected and transferred to MFC Analytical Lab for analysis. (R. Watson)

[INL] The pilot scale demonstration completed a series of technical discussions to clarify the process flowsheets and engineering design scope with the INL SME and MPR (the Design Agent). The technical discussions provided important requirements that were captured in the F\&ORs. A resource loaded basis of estimate was approved. A procurement order for a long lead instrument (Raman Spectrograph) was placed. (R. Watson)

[ANL] Over the past month, $2 \mathrm{~cm}$ and $3 \mathrm{~cm}$ contactor designs have been improved in order to reduce slugging behavior of the fluids flowing from the collection rings and through interstage lines. In addition, a more robust mounting system has been devised and prototyped (from acrylic) for the motor/rotor housing assembly. These design improvements should demonstrate performance improvements in reliability and capacity when compared with traditionally fabricated contactors. Preparations are currently being made for initial metal prints of these designs from 17-4 PH stainless steel. Zero-point and hold-up testing of rotor designs has been pause pending approval and authorization of the WCD.

Components were identified for which improved separations are needed and suggested revisions in separation factors are currently assumed for the UREX process. Steps were identified that will increase confidence and potentially improve the current assumptions, including:

1. Create D-value models for Sn and Sb using literature data and add them as components in AMUSE

2. Run the baseline flowsheet in AMUSE with $\mathrm{Sm}, \mathrm{Sn}, \mathrm{Ru}, \mathrm{Sb}$ included in the feed.

3. Evaluate whether modifications to the flowsheet (i.e. additional stages) are able to improve separations.

4. Evaluate whether small scale experiments to verify D-values would be necessary. (C. Pereira)

[PNNL] Personnel from PNNL visited INL and toured the facilities in which the Hybrid-ZIRCEX activities are taking place. The purpose of the trip was to gain a better understanding of the overall system and facility layout to support two PNNL-led tasks. These tasks are: (1) to evaluate the pros and cons of potential uranium conversion methods to be used to convert the purified uranyl nitrate stream to an oxide form, and (2) to evaluate and recommend points in the system in which on-line monitoring can be inserted to enhance process monitoring and control. Reports on these two subjects will be prepared in the coming months. (G. Lumetta)

\subsection{Early Design of Engineering Scale Demonstration}

[INL] The Hybrid ZIRCEX Demonstration Conceptual Design contract was executed on November $19^{\text {th }}$ with AECOM. A kickoff meeting was held the same day in Denver to review the objectives of the Demonstration and how these relate to the over design principles. Actions were identified and captured. (K. Perry)

[ANL] ECAR-4705 provided by INL regarding "Polished HALEU Product" composition and specifications for "Research Reactor Y-12 HALEU Metal," was reviewed in support of efforts to develop a UREX flowsheet for a glovebox contactor system at INL (C. Periera) 


\subsection{Transportation}

[INL] The M3FT-19IN030205042 milestone report, titled, "UO2 HALEU Transportation Package Evaluation and Recommendations," INL/EXT-19-56333 was submitted. This milestone report provides a status update on the research and investigations conducted on package concepts for HALEU transportation. Specifically, the report identifies two existing packaging designs, (1) the TN Americas TN-LC and (2) the NAC International OPTIMUSTM-L, that show the potential to be adapted for economical HALEU transportation. (J. Jarrell)

For more information on Material Recovery and Waste Forms Development contact Terry Todd (208) 526-3365 


\section{MPACT CAMPAIGN}

\subsection{Campaign Management}

\subsubsection{NTD \& Management Support}

[LANL] MPACT NTD and Federal Program Manager participated in NE-4 strategic planning meeting on November 11, 2019. MPCT NTD reviewed major FY20 objectives and noted that MPACT would benefit from NE and NE-4 prioritization efforts to align MPACT activities with NE technology developments. MPACT held its annual Fall meeting (telecon in 2019). The goal of the meeting was to review campaign objectives, discuss technical activities within the campaign for general coordination, and encourage MPACT researchers to begin thinking about priorities after FY20. The campaign discussed the importance of the Milestone 2020 deliverable and reviewed individual contributions and timelines towards meeting this deliverable. MPACT CAM reviewed work package manager responsibilities and emphasized the importance of meeting PICSNE reporting requirements. MPACT NTD participated in JFCS ERWG meeting in Daejeon ROK November 19-20, 2019. NTD travelled for DOE/NNSA as part of JFCS SSWG responsibilities but coordinated MPACT-developed technology field trials with ERWG counterparts.

\subsection{MRWFD/Advanced Nuclear Safeguards and Security Research}

\subsubsection{MSR Safeguards}

[ORNL] Interim report in preparation on the results of the dose assessment. Interim report in preparation on the preliminary signatures work, which lays the foundation for the L2 milestone task and collaboration with SNL. The project PhD student is developing an ORNL-TRANSFORM model of the ORNL thermal convection salt loop to benchmark the TRANSFORM MSDR simulations. A method to integrate the data from ORIGEN and TRANSFORM is being explored. Potential test beds are being explored.

\subsubsection{Microcalorimetry Consulting}

[LANL] Installation of the new control system for the SOFIA field test instrument is complete. Control of the adiabatic demagnetization refrigerator is now completely automated and very user-friendly. Initial results show improved base temperature and hold time, which will improve the ability to collect highstatistics data sets. The Bluefors SD dilution refrigerator cryostat system for the INL gamma spectrometer has been received and staged in the lab. Beginning a series of tests on multiplexing chips to understand and improve their stability under gamma irradiation. Completion of these tests is necessary before University of Colorado proceeds with final assembly of the new detector assembly for the SOFIA field test instrument.

\subsection{Safeguards and Security Supporting Technologies - Echem}

\subsubsection{Microfluidic Sampler}

[ANL] Formal review processes were carried out for the Raman spectroscopy system design and work planning and control documentation. A simplified manual actuation mechanism for the molten salt pump priming bellows was designed to replace an electrically-actuated mechanism that had failed during system testing. The new manual mechanism was designed with remote operation in mind and should be more robust than the failed component. 


\subsubsection{Bubbler for Measuring Density and Depth of Molten Salt}

[INL] The triple bubbler sensor was pulled out of the ER in HFEF for cleaning. Unfortunately, the air cell window where the water circulator system can be used has been under repair, so the cleaning has yet to be completed. In the lab, several experiments were conducted in aqueous solutions to gain insight to tip design and tube swapping, including error analysis between tubes. Preparations were made to start a molten salt experiment in January.

\subsubsection{OR Voltammetry}

[INL] The sensor was used to monitor the OR through weekly measurements. I procedure is under development and testing to explore how to get more repeatable data from the sensor as well as to capture the key measurement data.

\subsubsection{ER Voltammetry}

[ANL] Final operational guidelines and experimental documentation are being prepared for the package that is to be delivered to INL in January. It is expected that Milestone M2FT-20AN040104041-ER will be completed on time.

\subsection{Safeguards and Security Milestone 2020 - Echem:}

\subsubsection{Advanced Integration Methods}

[LANL] With the new SSPM data we have generated new source terms that will be used to create new Microcal spectograms. At the moment, the new SSPM data has a higher throughput so we are working on ingot size and once we have that figured out, that model will be used for generating new microcal data for integration and performance modeling.

\subsubsection{Security Facility Models}

[SNL] The vulnerability analysis of a generic echem facility is being performed to supplement the path analysis work. The existing security model is being modified to support the FY20 analysis.

For more information on MPACT contact Mike Browne at (505) 665-5056. 


\section{SYSTEMS ANALYSIS AND INTEGRATION (SA\&I) CAMPAIGN}

\subsection{Campaign Management}

[ANL, INL] Hosted a Webinar on Nov. $7^{\text {th }}, 2019$. The primary purpose of this Webinar is to introduce the Technology and System Readiness Assessment (TSRA) process, provide information on application of the process on an example nuclear energy system, and show how the TSRA Process could assist with the DOE-NE program integration. About 30 personnel from various DOE-NE offices and national labs participated in the Webinar.

[ANL] Participated in an NE-4 Strategy Session held in Washington, D.C., on November 13, 2019. Discussed the SA\&I Campaign priorities and challenges.

\subsection{NUCLEAR ENERGY SYSTEM PERFORMANCE (NESP)}

\subsubsection{Technology Maturity \& Economic Performance Potential of Micro- reactors}

[ANL] For evaluating technology maturity and economic performance of a gas-cooled micro reactor, a series of calls and meetings with HolosGen were held. In a meeting with Holosgen representatives in Washington D.C. on Nov. $18^{\text {th }}$, the company agreed to share information on their reactor design with the campaign. Separately, contacted Westinghouse Electric Company to inquire if they are willing to share information on the eVinci heat-pipe micro reactor design.

\subsubsection{Impacts of Foreign Energy Transition Policies}

[ANL] Gathered publicly available data on the impacts of energy policy changes in Korea, and Japan, which include the annual reports of utilities, electricity generation costs, energy sources, etc.

\subsubsection{Factors Impacting Nuclear Energy Share}

[ANL] Continued the collection of reference literature on the sustainability of nuclear energy in future markets and policy environments, from OECD/NEA, university, consulting companies, etc.

\subsubsection{Maintain/Update of Fuel Cycle Catalog}

[SNL]. We continued to work with the SNL SharePoint team to diagnose problems they were having with SharePoint that were affecting entering data into the catalog, but not affecting the public Nuclear Fuel Cycle Catalog.

\subsubsection{Transition Analysis Studies and Tools Development}

[ANL] Continued development of the Dakota/DYMOND coupling scheme to enable running multiple scenarios in parallel to generate data needed for uncertainty quantification and sensitivity analyses. Worked with PNNL (S. Kim) to obtain a higher resolution nuclear demand energy profile for reference scenario to be used in nuclear fuel cycle systems codes such as DYMOND for sensitivity analyses.

[INL] We have been investigating the feasibility of coupling the VISION simulation model to the RAVEN suite of sensitivity analysis and optimization tools in support of the milestone report due in June. Continued progress was made on integrating NEA benchmark results into the pending report writeup. 


\subsubsection{Quick Turn-Around Studies_}

[ANL] Information was collected and summarized for SA\&I campaign management on a variety of topics: Canadian initiatives for siting a small modular reactor at the CNL site; micro reactor technology development; recently announced Poland nuclear energy project; and UK small modular reactor concept proposed by Rolls Royce.

\subsection{ECONOMIC AND MARKET ANALYSIS FOR NUCLEAR ENERGY SYSTEMS (EMANES)}

\subsubsection{Improvement of ACCERT Algorithm}

[ANL] Began collecting data on the Landmark pyroprocessing facility.

\subsubsection{Daily Market Analysis of Load Following and Storage Impacts}

[ANL] Met with ANL Energy System division grid modeling experts to discuss their potential support to the SA\&I activity on daily market analysis.

[ANL] Met with P. Feroni of Westinghouse Company to discuss potential collaboration on economics analysis for their LFR system associated with thermal storage.

[ANL] Reviewed the "Folz Report" issued and publicly released at the request of EDF about feedback experience from French EPR Flamanville construction project.

\subsubsection{Cost Basis Report Enhancements}

[ANL] Developing internal campaign proposals on approaches for public release of the Cost Basis Report both effectively and frequently. Also continued to update and revise fuel fabrication cost modules in the Cost Basis Report.

For more information on Systems Analysis and Integration contact Temitope Taiwo (630) 252-1387. 


\section{JOINT FUEL CYCLE STUDY ACTIVITIES}

The third $4 \mathrm{~kg}$-scale test with irradiated LWR fuel in the oxide reduction system was completed, and preparations were made for the fourth test operation. Initial data indicate a $>90 \%$ conversion of oxide fuel to metal following oxide reduction and salt separation at this scale.

Tests to evaluate and demonstrate the capture of volatile fission products from heated fuel were completed using irradiated LWR fuel as the test material.

The second electrorefining test with irradiated LWR fuel was completed with the IRT equipment.

For more information on Joint Fuel Cycle Studies Activities contact Ken Marsden (208) 533-7864. 


\section{AFCI-HQ PROGRAM SUPPORT}

Site: University Research Alliance at West Texas A\&M University in Canyon TX, and the following universities: Ohio State University, University of Tennessee at Knoxville, Georgia Institute of Technology, University of Idaho, Colorado School of Mines, University of South Carolina, Florida State University, Northwestern University, Clemson University, North Carolina State University, University of Utah, University of Chicago, Columbia University, University of Toledo, and other universities.

Universities engaged in Nuclear Technology research via URA programs since 2001:

Boise State University

Boston College

Clemson University

Colorado School of Mines

Columbia University

Georgia Institute of Technology

Georgetown University

Idaho State University

Florida International University

Florida State University

Kansas State University

Massachusetts Institute of Technology

Missouri University of Science and

Technology

North Carolina State University

Northern Illinois University

Northwestern University

Ohio State University

Oregon State University

Pennsylvania State University

Purdue University

Rensselaer Polytechnic Institute

Rutgers University

Texas A\&M University

University of Arkansas
University of California at Berkeley

University of California at Santa Barbara

University of California at Davis

University of Chicago

University of Cincinnati

University of Florida

University of Idaho

University of Illinois at Urbana-Champaign

University of Michigan

University of Missouri

University of Nevada at Las Vegas

University of New Mexico

University of North Texas

University of Notre Dame

University of Ohio

University of South Carolina

University of Tennessee at Knoxville

University of Texas at Austin

University of Toledo

University of Utah

University of Virginia

University of Wisconsin

Vanderbilt University

Virginia Commonwealth University

Washington State University 


\subsection{Innovations in Nuclear Technology R\&D Awards}

\subsubsection{University Programs}

\subsubsection{Summary Report}

On November 18, seven of the 2019 Innovations Awards winners presented their research at the Innovations in Nuclear Technology R\&D Awards special session at the American Nuclear Society Winter Meeting in Washington DC. The session was chaired by Mr. Andrew Griffith, Deputy Assistant Secretary for Nuclear Fuel Cycle and Supply Chain at the DOE Office of Nuclear Energy. Desktop awards were presented to the students by Mr. Griffith, and photos were taken. Some of the other Innovations Awards winners from current and previous years attended the session, and all of the winners were honored with a celebratory dinner after the session. Mr. Griffith also attended the dinner, along with other invited guests from the DOE, industry, and national laboratories.

Seven award-winning papers were presented:

Efficient Capture of Perrhenate and Pertechnetate by a Mesoporous-Organic Framework and Crystallographic Examination of Binding Motifs

Riki Drout, Northwestern University

Synthesis of the First All-Uranium(V) Borate

Kristen Pace, University of South Carolina

Incorporating Variable Moderation Elements into the FHR Design to Increase Both Cycle Length and Discharge Burnup

Vedant Mehta, Georgia Institute of Technology

Overstepping Löwenstein's Rule: A Route to Unique Uranium Aluminophosphate Frameworks

Christian Juillerat, University of South Carolina

Photopolymerized Plastic Scintillators Capable of Neutron and Gamma Ray Discrimination

Allison Lim, Colorado School of Mines

Bis-(2-ethylhexyl) Phosphoric Acid Functionalized Carbon Nanoparticles for Chromatographic Lanthanide Separations

Erin Bertelsen, Colorado School of Mines

An Overview of Methodologies for Cybersecurity Vulnerability Assessments Conducted in Nuclear Power Plants

John Peterson, University of Idaho

In-Pile OFDR Sensing with Fiber Bragg Gratings in Sapphire Optical Fiber

Kelly McCary, Ohio State University

University Research Alliance began preparing reimbursements for the winners' travel expenses from the ANS meeting.

University Research Alliance mailed desktop awards to the 2020 award winning students who did not attend the ANS Meeting. 
University Research Alliance began preparations for the 2020 Innovators' Forum, tentatively scheduled for May 2020.

For more information on the University Research Alliance contact Cathy Dixon (806) 651-3401. 